\title{
FTIR spectroscopy for estimation of efavirenz in raw material and tablet dosage form
}

\author{
*Nareddy Preethi Reddy, Yenumula Padmavathi, Perika Mounika and Akari Anjali \\ Department of Pharmaceutical Analysis and Quality Assurance, G. Pulla Reddy College of Pharmacy, Hyderabad, Telangana, India
}

\begin{abstract}
A Fourier transform infrared (FTIR) spectrophotometric method was developed for rapid and direct measurement of efavirenz in pharmaceutical formulations. The method involves extraction of efavirenz from tablets with chloroform by sonication and the direct measurement of the absorbance in liquid phase using a reduced path length cell. In general, the spectrum was measured in transmission mode. The equipment was configured to collect a spectrum at $8 \mathrm{~cm}^{-1}$ resolution and $45 \mathrm{scans}$ per sec . The spectra were collected between $4000 \mathrm{~cm}^{-1}$ and $450 \mathrm{~cm}^{-1}$, the band obtained at $1750 \mathrm{~cm}^{-1}$ (carbonyl group) showed intense, clear peak in the liquid phase for quantitation. The method was validated as per ICH guidelines. The method fulfilled most validation requirements in the linearity range $200-1000 \mathrm{\mu g} / \mathrm{mL}$. The coefficient of determination, limit of detection and quantification was found to be 0.993 , $49.12 \mu \mathrm{g} / \mathrm{mL}$ and $148.84 \mu \mathrm{g} / \mathrm{mL}$ respectively. Results of developed FTIR method were compared with the results obtained with the existing UV method statistically by using t-test, which indicated that there is no significant difference between the methods at $\mathrm{P}=0.05$. The proposed FTIR method reduces the solvent consumption and also eliminates the use of reagents. Thus the developed method offers a good alternative for the quantitative estimation of efavirenz in bulk and pharmaceutical dosage forms and also to quantify efavirenz when combined with other API in the same dosage form.
\end{abstract}

Key Words: Efavirenz, FTIR, method validation, ICH guidelines.

\section{INTRODUCTION}

Efavirenz is an antiretroviral agent used for the treatment of HIV infection and widely used in the highly active antiretroviral (HAART) therapy. It belongs to the class of nonnucleoside reverse transcriptases which are chemically diverse compounds that bind to the reverse transcriptase enzyme near the catalytic site and denature it. Chemically it is (4s)-6-chloro-4-(2-cyclopropylethylnyl)-4 (trifluoromethyl)-2,4-dihydro1H-3,1-benzoxazin-2-one (figure 1). It is soluble in dimethyl sulfoxide (DMSO), chloroform, lower alcohols and slightly soluble in toluene (Rang et al., 2012; Drugs.com, 2014).

In the present decade, several UV spectrophotometric, HPLC and LC-MS/MS methods have been reported so far for the estimation of efavirenz alone and in combination with other drugs in pharmaceutical samples (Kadam et al., 2012; Bansal et al., 2013; Ahmed et al., 2013; Matkovic et al., 2005). The official methods for the determination of efavirenz as a bulk drug and in tablets are based on liquid chromatography (IP, 2011). However, until now no direct Fourier transform infrared (FTIR) spectroscopy method has been recommended for the quantitative determination of efavirenz in solid dosage forms. Because of its simplicity and availability, FTIR is a technique which can be used in pharmaceutical quality control laboratories not only for the qualitative, but also for the quantitative purposes. Since the wave number and the respective intensity of an absorption maximum depends on a particular group of the chemical structure of a substance, this measurement can be used to quantitatively determine a substance (Pavia et al., 2008). FTIR spectrum of efavirenz (figure 2) depicts how rich the

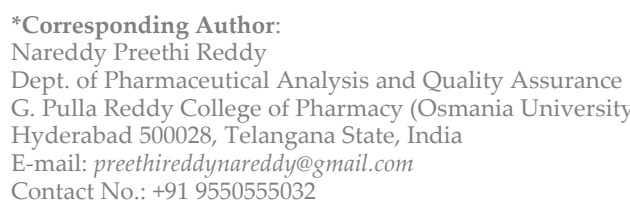

structure of efavirenz is in regards to diverse groups which absorb in the mid-IR (MIR) region. For the past two decades, the transmission FTIR spectroscopy has underwent significant application for the quantitative purposes, several in the field of pharmaceutical analysis.

As per above, for the identity verification and purity of an API and for detection of any spectral interference from the excipients the spectrum of an FTIR can be used. A calibration curve approach method is used for analyzing the absorption spectrum of an FTIR. However, it usually requires the chemometric methods in order to improve its data quality whenever applicable. For the quantitative analysis of an absorption spectrometry, the main basis is the Bouguer-Beer-Lambert law. FTIR methods are simple, faster than chromatographic methods. They are cost effective as there is less consumption of solvents (Nikolic, 2011; Gallignani and Brunetto, 2004). The developed method was validated as per ICH guidelines and the results are statistically evaluated and compared with that of the existing UV spectrophotometric method ( $\mathrm{ICH}, 2005)$.

\section{MATERIALS AND METHODS}

\section{Equipment}

A Fourier Transform Infrared Spectrophotometer 8400S (Shimadzu, Kyoto, Japan) equipped with a sensitive pyroelectric detector with a DLATGS (L-alanine doped deuterated triglycine sulphate) element, a Michelson interferometer (30 incident angle), a Germanium coated $\mathrm{KBr}$ plate, and a globar IR source was employed for FTIR spectra acquisition. A Wilmad Lab glass FTIR liquid transmission cell was used for sampling. Its circular configuration was a general purpose liquid transmission cell. It involved $\mathrm{NaCl}$ windows (32 $\mathrm{mm}$ diameter, $3 \mathrm{~mm}$ thick) and an appropriate PTFE spacer of $0.1 \mathrm{~mm}$ optical path length. The sample was introduced by filling ports using a $3 \mathrm{~mL}$ syringe. 


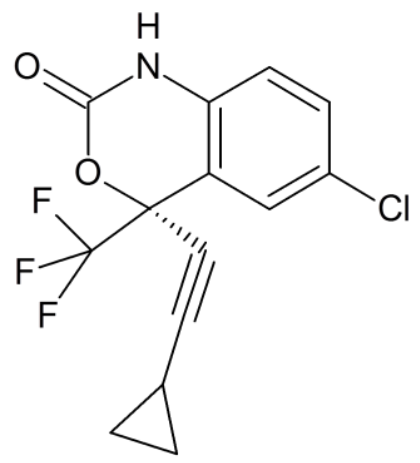

Figure 1: Structure of Efavirenz.

\section{Reagents and samples}

Efavirenz raw material was kindly provided by Aurobindo Pharmaceuticals, Hyderabad, India. Potassium bromide (SD fine chemicals limited), Chloroform (Sisco Research Laboratories Pvt. Ltd), Methanol (Merck specialties private limited) were purchased. Commercial pharmaceutical $600 \mathrm{mg} / \mathrm{Tab}$ were purchased from local market manufactured by Hetero Labs limited, Hyderabad, India.

\section{Preparation of standard solution}

A $1.0 \mathrm{mg} / \mathrm{mL}$ efavirenz stock solution was prepared in chloroform. After being diluted with chloroform, increasing volumes of efavirenz stock solutions were quantitatively transferred to a set of $10 \mathrm{mLvolumetric}$ flasks to provide solutions within the $200-1000 \mu \mathrm{g} / \mathrm{mL}$ concentration range.

\section{Sample preparation}

Twenty tablets were accurately weighed, finely pulverized and thoroughly mixed.An accurately weighed portion of pulverized tablets equivalent to $25 \mathrm{mg}$ of efavirenz was transferred to a $25 \mathrm{~mL}$ volumetric flask, $9 \mathrm{~mL}$ of diluting solvent (chloroform) was added, and was sonicated for $30 \mathrm{~min}$. After cooling, the diluting solvent was added to bring the volume to the mark. Finally, it was mixed, centrifuged at $3000 \mathrm{rpm}$ for $5 \mathrm{~min}$, and filtered, discarding the first $2.5 \mathrm{~mL}$ of the filtrate. All sample solutions were filtered through $0.22 \mu \mathrm{m}$ analytical Nylon filters. Samples for the standard addition technique were obtained by increasing volumes $3.2 \mathrm{~mL}$. $4.0 \mathrm{~mL}$ and $4.8 \mathrm{~mL}$ of the $1 \mathrm{mg} / \mathrm{mL}$ efavirenz stock solution to a set of $10 \mathrm{mLvolumetric} \mathrm{flasks} \mathrm{containing} 400 \mu \mathrm{g} / \mathrm{mL}$ of sample solution. They were then quantitatively diluted to obtain solutions within the nominal concentration range.

\section{Method validation}

The developed FTIR method for quantitative estimation of efavirenz in tablets was validated according to the ICH guidelines for the following parameters- limit of detection (LOD) and limit of detection (LOQ), linearity, precision and accuracy.

\section{RESULTS AND DISCUSSION}

\section{Optimization of FTIR conditions}

As per beer's law the relation between concentration and absorbance is linear and proportional, absorbance mode is selected in the method development for quantitation of efavirenz and all IR spectra are obtained in absorbance mode. Apodization function "Happ-Genzel" was selected
Table 1: Standard calibration curve data for efavirenz.

\begin{tabular}{ccc}
\hline Sr. No & Concentration $(\mu \mathrm{g} / \mathrm{mL})$ & Absorbance* A \\
\hline 1 & 200 & 0.04761 \\
2 & 400 & 0.08834 \\
3 & 600 & 0.12754 \\
4 & 800 & 0.15708 \\
5 & 1000 & 0.19219 \\
\hline${ }^{*}$ Average of three determinations
\end{tabular}

for normal measurement. As very few solvents are transparent in IR region, based on drug solubility chloroform and dimethyl sulfoxide were selected for IR analysis by liquid sampling technique. In chloroform, better peak intensity was observed and chloroform is transparent throughout the region of $800-5000 \mathrm{~cm}^{-1}$ hence it was selected as solvent for preparation of solutions. The frequency range of $400-4000 \mathrm{~cm}^{-1}$ (Mid IR region) was selected for IR analysis. As the number of scans increases $\mathrm{S} / \mathrm{N}$ ratio increases, 45 scans were selected for better $\mathrm{S} / \mathrm{N}$ ratio. Resolution $8 \mathrm{~cm}^{-1}$ was selected for better peak to peak separation. Beer-Lambert's law was obeyed over the concentration range of $200-1000 \mu \mathrm{g} / \mathrm{mL}$. The band chosen for quantization should be in a region of the spectrum free from absorption by other possible components of the sample.

\section{Spectral characterization of efavirenz in chloroform}

Efavirenz is soluble in water. It is also soluble in DMSO, chloroform, lower alcohols and slightly soluble in toluene. We selected chloroform taking into account efavirenz's solubility, volatility and IR transparency. This is considered a green chemical solvent due to its properties, such as low toxicity, low water miscibility and low volatility. Using chloroform as the background, transparency zones were found in the IR finger print range $\left(\mathrm{v} / \mathrm{cm}^{-1}\right)$ as follows: 1370-1270, 1240-1120 and 1050-500. The FTIR spectrum of efavirenz obtained in the solid phase, (KBr pellet) shows well defined bands with relatively high intensity in the $1800-400 \mathrm{~cm}^{-1}$ wave number range in transmittance and absorbance mode (figure 2 and 3). Using the $\mathrm{KBr}$ pellet, comparison of the efavirenz analyte FTIR spectrum $v$ s. the efavirenz reference spectrum from the International Pharmacopoeia website showed an excellent frequency correlation. The expected bands in the IR spectrum of efavirenz are $\mathrm{N}-\mathrm{H}$ strong stretch at $3317.3 \mathrm{~cm}^{-1}, \mathrm{C}=\mathrm{O}$ stretch at $1749.7 \mathrm{~cm}^{-1}, \mathrm{CH}$ at 2248.0, C-F at $1496.9 \mathrm{~cm}^{-1}, 1329$ $\mathrm{cm}^{-1}, \mathrm{C}-\mathrm{Cl}$ stretch at $1038.3 \mathrm{~cm}^{-1}$.

Therefore, taking into account the above information, the efavirenz FTIR spectrum, using chloroform as background, showed two notable spectral bands in the MIR with maximum wave numbers located at $1750 \mathrm{~cm}^{-1}$ and $1500 \mathrm{~cm}^{-1}$ corresponding to the carbonyl group $\mathrm{C}=\mathrm{O}$, $\mathrm{C}=\mathrm{C}$ aromatic ring respectively (figure 5). Among which $\mathrm{C}=\mathrm{O}$ group showed clear, intense peak which was increased linearly as the concentration is increased and selected for quantitative analysis of efavirenz.

Pressed pellet technique is suitable for handling of solids. For quantitative estimation, it is difficult to prepare low concentrations of sample by pressed pellet technique, hence liquid sampling technique is used and the solutions were prepared in chloroform solvent. The liquid samples were analysed by using liquid cells. The blank spectrum of chloroform and efavirenz in chloroform are shown in figure 4 and 5 . 


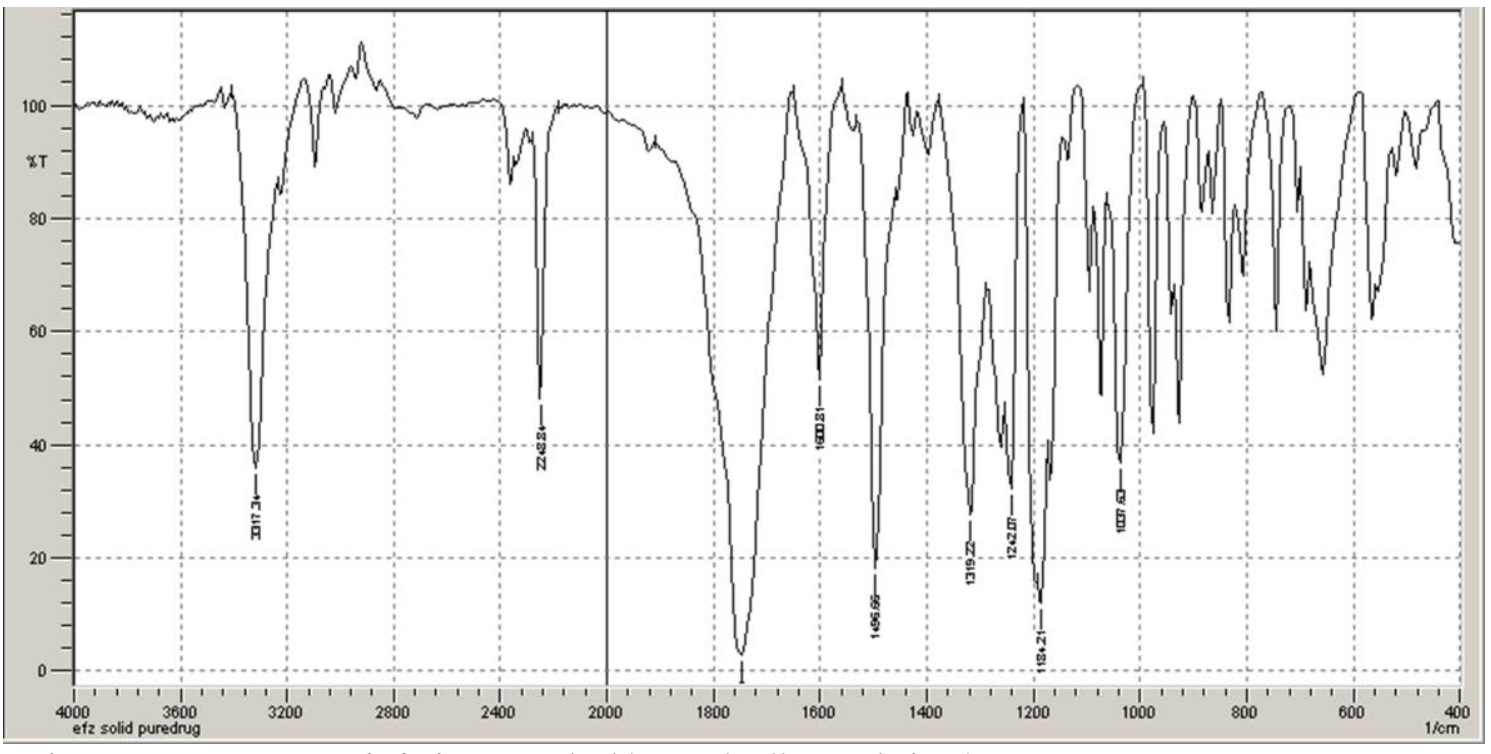

Figure 2: FTIR spectrum of Efavirenz standard (Pressed Pellete Technique).

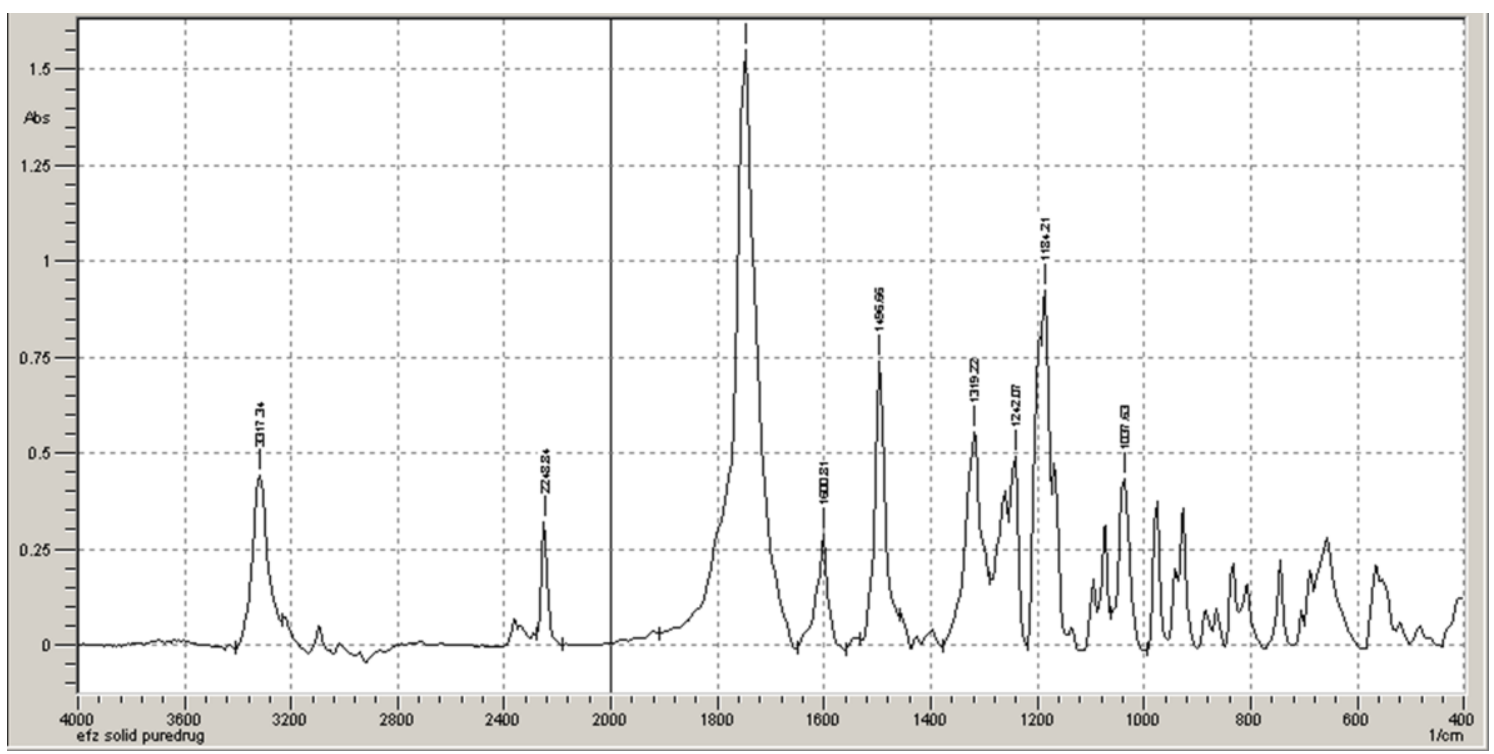

Figure 3: FTIR spectrum of efavirenz standard (Pressed Pellete Technique) in absorbance mode.

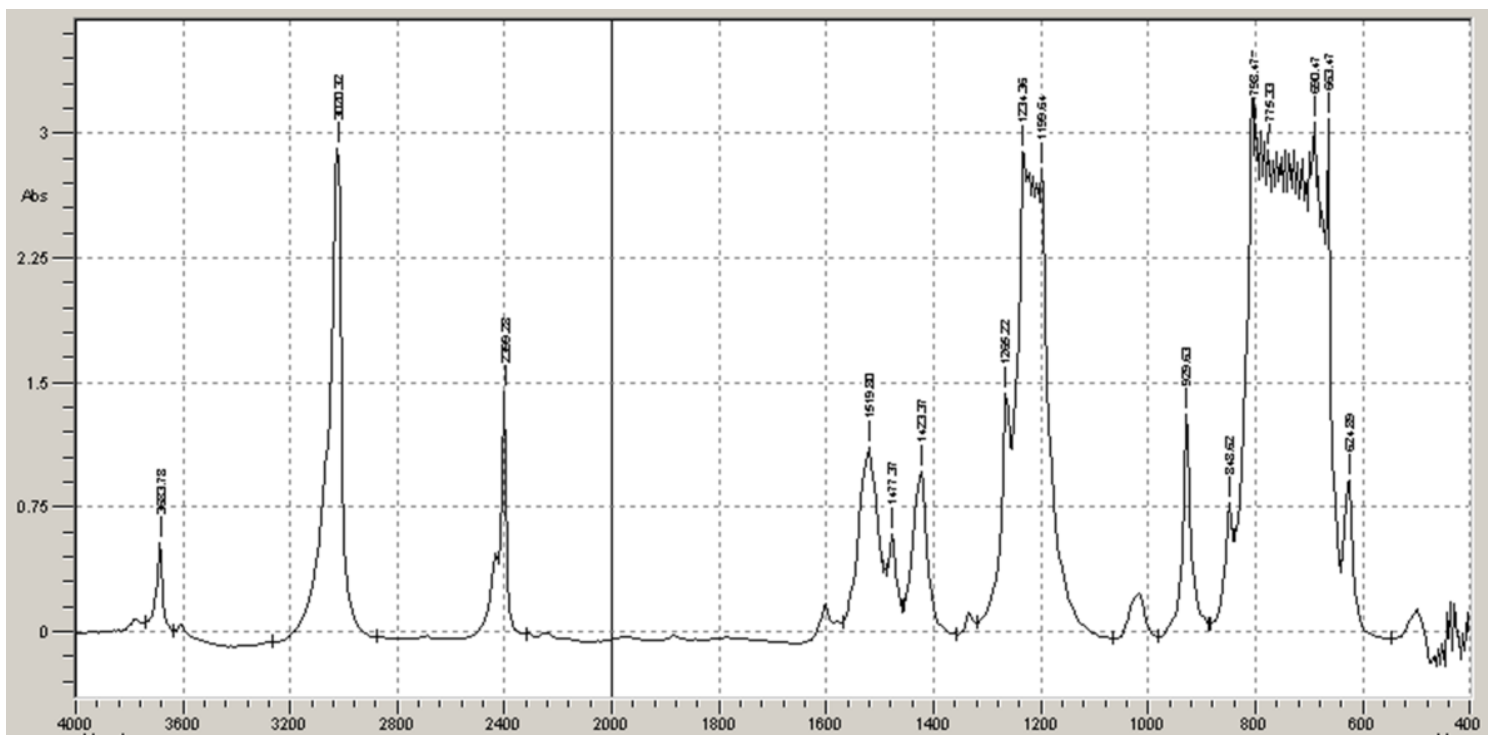

Figure 4: Blank spectrum of chloroform. 


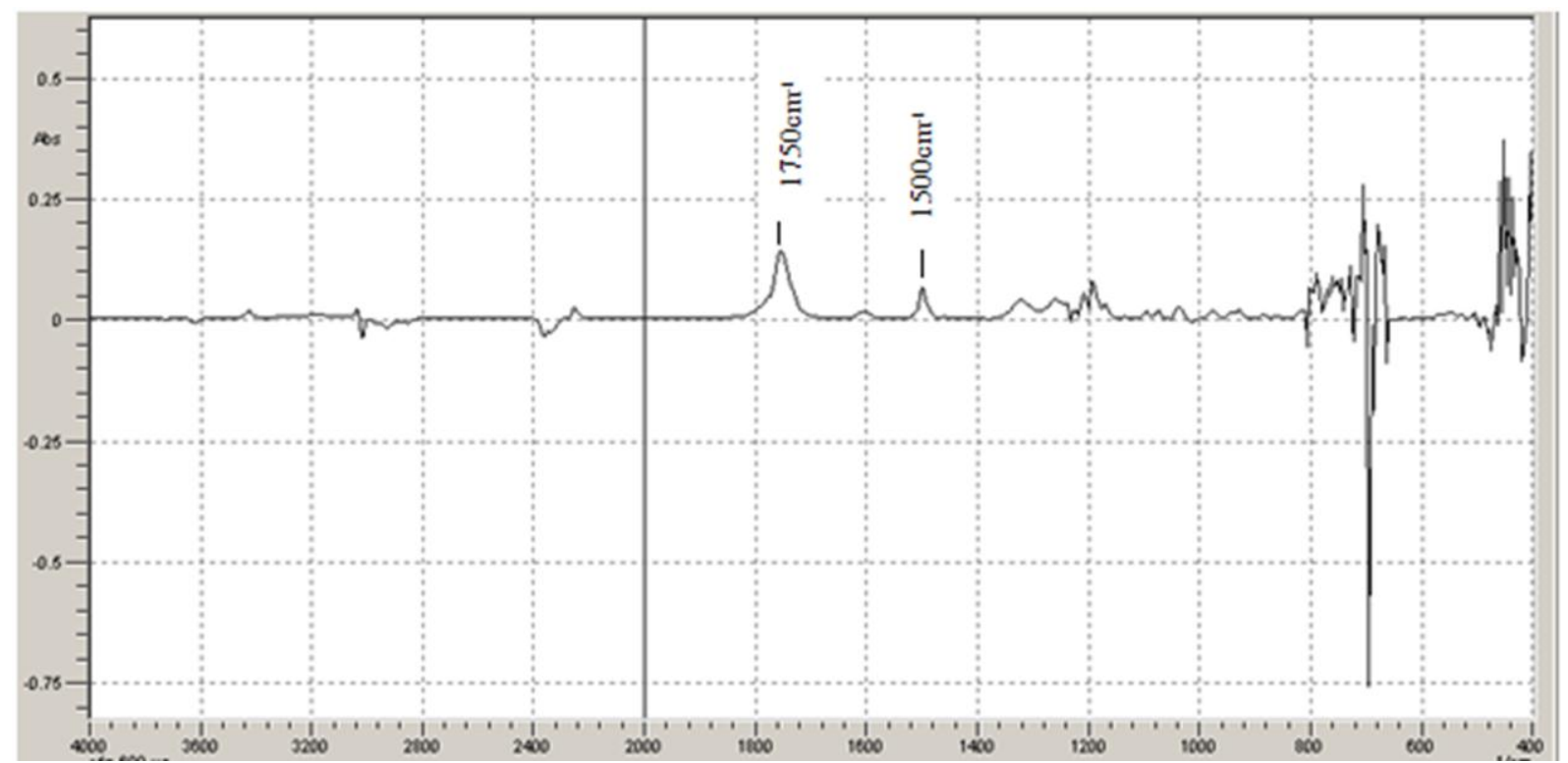

Figure 5: FTIR spectrum of efavirenz standard in chloroform (liquid sampling technique).

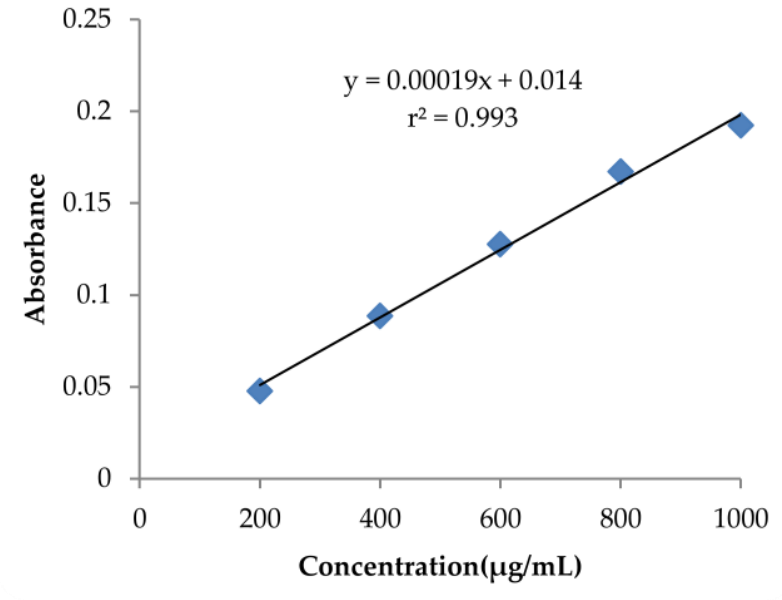

Figure 6: Standard calibration curve for efavirenz standard.

\section{Method validation parameters \\ Linearity data}

From the simple regression line described in figure 6, it was demonstrated acceptable efavirenz linearity over the $200-1000 \mu \mathrm{g} / \mathrm{mL}$ range with a quantification limit of $148 \mu \mathrm{g} / \mathrm{mL}$. Furthermore, the y-intercept variability resulted in less than $1 \%$ of the response obtained at the targeted level which is usually an acceptable criterion. The statistical significance of the regression line $\left(y=0.00019 x+014, r^{2}=0.993\right)$ also revealed that the slope is not zero, which in turn suggested that changes in the concentration variable are highly associated with the changes in the response variable (table 1).

\section{Limit of detection and limit of quantitation}

The FTIR method developed was sensitive with detection level $49.117 \mu \mathrm{g} / \mathrm{mL}$ and quantitation level $148.842 \mu \mathrm{g} / \mathrm{mL}$. They are calculated by using standard deviation method.

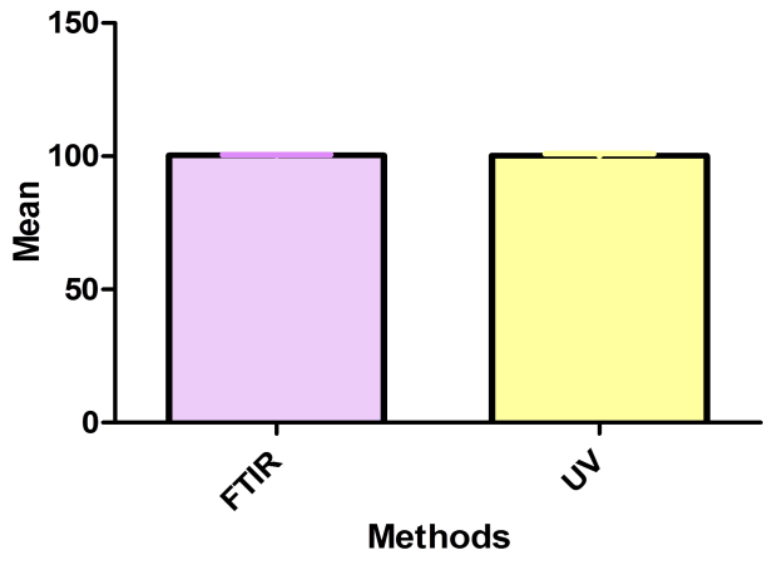

Figure 7: Bar diagram showing mean \% recovery of FTIR and UV.

\section{Precision}

The precision of the developed analytical method was assessed by reporting repeatability, intra-day precision and inter-day precision. There was no much difference in absorbance values measured in sessions of the day and for three consecutive days for checking robustness of the method. The calculated RSD values are low and indicate the precision of the method (table 2, 3).

\section{Accuracy}

Considering that the expected recovery depends on sample matrix, sample processing procedure and the analyte concentration, the accuracy of the proposed method can be considered suitable for determining efavirenz content in solid dosage pharmaceutical products (table 4).

\section{For drug substance}

The calculated amounts of pure efavirenz at three different levels were near to the actual values, indicate the 
Table 2: Intra-day precision data for Efavirenz.

\begin{tabular}{|c|c|c|c|c|c|c|}
\hline \multirow{2}{*}{ Sr. No. } & \multirow{2}{*}{ Conc. $(\mu g / m L)$} & \multicolumn{3}{|c|}{ Mean of Absorbance* } & \multirow{2}{*}{ Mean $^{*} \pm$ SD } & \multirow{2}{*}{$\%$ RSD } \\
\hline & & Morning & Afternoon & Evening & & \\
\hline 1 & 400 & 0.0872 & 0.0873 & 0.0892 & $0.0879 \pm 0.00112$ & 1.2821 \\
\hline 2 & 600 & 0.131 & 0.1276 & 0.1282 & $0.1289 \pm 0.00181$ & 1.408 \\
\hline 3 & 800 & 0.1698 & 0.166 & 0.1716 & $0.1691 \pm 0.00285$ & 1.6907 \\
\hline
\end{tabular}

*Average of three determinations

Table 3: Inter-day precision data for Efavirenz.

\begin{tabular}{|c|c|c|c|c|c|c|}
\hline \multirow{2}{*}{ Sr. No. } & \multirow{2}{*}{$\begin{array}{c}\text { Conc. } \\
(\mu \mathrm{g} / \mathrm{mL})\end{array}$} & \multicolumn{3}{|c|}{ Mean Absorbance* A } & \multirow{2}{*}{ Mean \pm SD } & \multirow{2}{*}{$\%$ RSD } \\
\hline & & $1^{\text {st }}$ day & $2^{\text {nd }}$ day & $3^{\text {rd }}$ day & & \\
\hline 1 & 400 & 0.0872 & 0.0849 & 0.0873 & $0.0864 \pm 0.00135$ & 1.5717 \\
\hline 2 & 600 & 0.1310 & 0.1270 & 0.1305 & $0.1295 \pm 0.00217$ & 1.6826 \\
\hline 3 & 800 & 0.1698 & 0.1727 & 0.1696 & $0.1704 \pm 0.00198$ & 1.1654 \\
\hline
\end{tabular}

*Average of three determinations

Table 4: Accuracy data for efavirenz drug substance.

\begin{tabular}{|c|c|c|c|c|c|c|}
\hline Sr. No. & Accuracy level & $\begin{array}{c}\text { Conc. } \\
(\mu \mathrm{g} / \mathrm{mL})\end{array}$ & Absorbance A & $\begin{array}{c}\text { Calculated } \\
\text { conc. }(\mu \mathrm{g} / \mathrm{mL})\end{array}$ & Mean \pm SD & $\%$ RSD \\
\hline \multirow{4}{*}{1} & \multirow{4}{*}{$80 \%$} & \multirow{4}{*}{320} & 0.0742 & 316.84 & \multirow{4}{*}{$322.1 \pm 4.821$} & \multirow{4}{*}{1.496} \\
\hline & & & 0.0754 & 323.15 & & \\
\hline & & & 0.076 & 326.31 & & \\
\hline & & & 0.0894 & 396.84 & & \\
\hline \multirow[t]{3}{*}{2} & \multirow[t]{3}{*}{$100 \%$} & \multirow[t]{3}{*}{400} & 0.0912 & 406.31 & \multirow[t]{3}{*}{$401.57 \pm 4.735$} & \multirow[t]{3}{*}{1.179} \\
\hline & & & 0.0903 & 401.57 & & \\
\hline & & & 0.10397 & 473.15 & & \\
\hline \multirow[t]{2}{*}{3} & \multirow[t]{2}{*}{$120 \%$} & \multirow[t]{2}{*}{480} & 0.10368 & 471.57 & \multirow[t]{2}{*}{$475.78 \pm 5.981$} & \multirow[t]{2}{*}{1.257} \\
\hline & & & 0.10572 & 482.63 & & \\
\hline
\end{tabular}

*Average of 3 determinations

Table 5: Recovery data for Efavirenz.

\begin{tabular}{|c|c|c|c|c|c|c|}
\hline $\begin{array}{l}\dot{0} \\
\text { Zे }\end{array}$ & $\begin{array}{l}\overline{0} \\
\frac{0}{0} \\
\frac{0}{0} \\
\text { के }\end{array}$ & 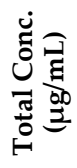 & 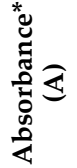 & ن⿺辶卂 & 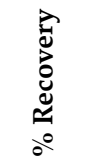 & 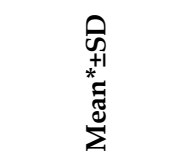 \\
\hline 1 & $80 \%$ & 8.1 & 0.458 & 8.11 & 100.227 & \\
\hline 2 & $100 \%$ & 9 & 0.497 & 8.9 & 98.889 & $100.207 \pm 1.3081$ \\
\hline 3 & $120 \%$ & 9.9 & 0.567 & 10.14 & 101.505 & \\
\hline
\end{tabular}

accuracy of the method for determination of pure efavirenz. From the above data it was found that the $\%$ RSD (acceptance criteria $<2 \%$ ) values are within the acceptance limits.

\section{For drug product (Recovery study)}

The method was found to be accurate for determination of efavirenz in tablets, as the \% recovery values calculated are found to be within the acceptable limits (table 5).

\section{FTIR and UV results comparison}

The recovery values of FTIR and UV methods were compared by applying t-test for paired sample. The t-test was performed to prove that there is no significant difference in the recovery of new FTIR and existing UV method.

\section{T-test}

"There is no significant difference in the recovery values of new FTIR method and existing UV method" is the null hypothesis selected for comparison (Khan and Khanum, 2008). The calculated $p$-value is lesser than the tabulated value $(p=0.05)$. It is clearly indicated that the two recovery
Table 6: Analysis of Efavirenz by two methods.

\begin{tabular}{cccc}
\hline Method & Mean (\%) & RSD (\%) & N \\
\hline FTIR & 100.703 & 0.7335 & 9 \\
UV & 100.207 & 1.3054 & 9 \\
\hline N= Number of determinations at three levels each three replicates
\end{tabular}

Table 7: T-test data.

\begin{tabular}{|c|c|c|c|c|}
\hline \multirow{2}{*}{$\begin{array}{l}\text { Sr. } \\
\text { No. }\end{array}$} & \multicolumn{2}{|c|}{ Recovery (\%) } & \multirow{2}{*}{$\begin{array}{c}\text { Difference } \\
\mathrm{X} 1-\mathrm{X} 2=\mathrm{d}\end{array}$} & \multirow{2}{*}{$\left(X_{1}-X_{2}\right)^{2}=d^{2}$} \\
\hline & FTIR $\left(X_{1}\right)$ & $\mathrm{UV}\left(\mathrm{X}_{2}\right)$ & & \\
\hline 1 & 100.411 & 100.227 & 1.184 & 1.4018 \\
\hline 2 & 99.937 & 98.889 & 1.048 & 1.0983 \\
\hline 3 & 100.761 & 101.505 & -0.744 & 0.5535 \\
\hline Total & & & $\Sigma \mathrm{d}=1.488$ & $\Sigma \mathrm{d}^{2}=3.052$ \\
\hline
\end{tabular}

values are very much similar and difference is not significant. Therefore, the null hypothesis stating that there is no significant difference between the recovery values of two methods, new FTIR method and existing UV method is accepted at $\mathrm{p}=0.05$. The difference between the recovery values of two methods is not a real difference because the level of significance is very low (table 7).

\section{CONCLUSION}

The developed FTIR method for determining efavirenz based on IR measurements in absorbance mode in the liquid phase, fulfilled most validation requirements in a range of concentrations suitable for quality control of both pure drug as active pharmaceutical ingredient and solid dosage forms. Therefore, this can be used as a quality control method as alternative in pharmaceutical industry. FTIR in the transmission mode mainly used for the identification of API in raw materials and finished products but undervalued for quantitative purposes. By 
comparison with compendial and non-compendial analytical methods, the proposed FTIR method reduces solvent consumption and eliminates the use of reagents. The sensitivity of the method can be increased in further studies by taking derivative IR spectra using the solvents which are transparent in IR region.

\section{REFERENCES}

Ahmed, S., Sheraz, M.A, Yorucu, C., Rehman, I.U. (2013). Quantitative determination of Tolfenamic acid and its pharmaceutical formulation using FTIR and UV spectrometry, Central European Journal of Chemistry, 11(9): 1533-1541. [DOI]

Bansal, R., Guleria, A., \& Acharya. (2013). FT-IR method development and validation for quantitative estimation of zidovudine in bulk and tablet dosage form. Drug Res (Stuttg), 63(4): 165-170. [DOI]

Drugs.com. - Efavirenz. (2014) Auckland, New Zealand: Drug. [Link]

Gallignani, M., Brunetto, M.R. (2004). Infrared detection in flow analysis developments and trends (review), Talanta, 64(5): 1127-1146. [DOI]

ICH, Q2 Validation of Analytical Procedures: Text and Methodology. International Conference on Harmonization of Technical Requirements for Registration of Pharmaceuticals for Human Use, ICH harmonized Tripartite Guideline, Nov 2005.
Kadam, A.A.,Babu, C.J.G, Perumal, R.V., Channabasavaraj, K.P., Mani, T.T. (2012). Development and validation of UV spectrophotometric method for the quantitative estimation of efavirenz in bulk and pharmaceutical dosage form, American Journal of PharmTech Research, 2(1): 325-330.

Khan, I.A. and Khanum, A. (2008). Fundamentals of Biostatistics, $3^{\text {rd }}$ edition, Publisher: Ukaaz Publications, Hyderabad, India.

Matkovic, S.R., Valle, G.M. and Briand, L.E. (2005). Quantitative analysis of Ibuprofen in Pharmaceutical formulation through FTIR spectroscopy, Latin American Applied Research, 35(3): 189-195.

Nikolic, G.S. (2011). Fourier transforms-New analytical approaches and FTIR strategies, Publisher: InTech, USA. [DOI]

Pavia, D.L., Lampman, G.M., Kriz, G.S., Vyvyan, J.A. (2008). Introduction to Spectroscopy, California, $4^{\text {th }}$ edition, Publisher: Brooks/Cole, Cengage Learning, CA, USA.

Rang, H.P., Dale, M.M., Ritter, J.M., Flower, R.J., \& Henderson, G. (2012). Pharmacology, $7^{\text {th }}$ edition, Spain, Elsevier Churchill Livingstone. [DOI]

The Indian Pharmacopoeia Commission (2011). Indian Pharmacopoeia. Ghaziabad, India. [Link] 